\title{
PROVIDING PREMIUM SMS SERVICES FOR MOBILE PHONES
}

Usability based on networks of user - developer relationships

\author{
Petter Nielsen and Jo Herstad \\ University of Oslo, Department of Informatics, Norway
}

\begin{abstract}
In this paper we argue for the need to expand from a perspective on a single user - developer relation in designing usability to a perspective on usability as dependent on a multi-layered and distributed network of relations between multiple and diverse actors. Based on an empirical study of the successful premium SMS services for mobile phones in the Norwegian market we make explicit the user - developer relationships related to usability in a service providing context. We describe this context with a network perspective based on the specific concepts of value networks (Stabell and Fjellstad 1998). This rich analytical perspective appreciates the critical aspects of the service providing context and provides support in solving the primary usability challenges related to premium SMS services.
\end{abstract}

Key words: Premium SMS services; usability; value networks; user - developer relationships.

\section{INTRODUCTION}

From a system development perspective premium SMS services for mobile phones are rather simple and mundane. The focus of this paper is to introduce a different perspective on these services, making explicit new, important and indeed motivating challenges for system developers. To make these issues explicit we discuss the nature of the service providing context, the challenges of designing usability in this context and how these challenges should be appreciated and handled.

In general premium SMS services are under-researched and the concept of mobile services is in itself vaguely defined (Sørensen et al. 2002). What we can expect from these services is also still an open question (Carlsson 
and Walden 2002). Premium SMS services and their related business models have had a certain attention in M-commerce conferences (for example Anckar and D'Incau 2002; van de Kar et al. 2003). These contributions do however primarily focus on describing state-of-the art services and business models. They do not focus on how services are provided, the constituencies of the networks they are based on and how usability challenges are handled.

In 1997, premium SMS services for mobile phones were in Norway solely developed and provided by mobile network providers. Today, the situation is a different one as premium SMS services are based on a network of actors making up the final service to the end-users (mobile phone subscribers) with the required usability. These services are not only enabled by the transportation of content from the content producers to the end-users, but also services supporting acquisition, aggregation, market-wide-access, advertising, copyright handling etc. The system developers engaged in developing and providing these services do however have inadequate support in current system development methods. These methods are primarily supporting the technical development of software as packages, and not providing services within a context where there is more than one given user - developer relation, relations that have to be created and continuously maintained to create the necessary usability for the end-user.

In this paper we contribute with insights in a relatively novel context for system development. As this context involves a different nature of relations between users and developers, it also requires new approaches to usability design. Introducing and showing the appropriateness of using the concepts of value networks (Stabell and Fjellstad 1998) as an analytical lens, we suggest one approach to make visible and appreciate the critical factors within this context.

The research reported here is based on interviews conducted by one of the authors during 2003 and 2004. Interviews were held with the two mobile network providers in Norway as well as with 6 different content providers. Four interviews were in addition to this held with influential governmental agencies. All interviews were recorded and fully transcribed. The interviews were open-ended, but had a focus on the various actors' roles as well as the usability challenges they were struggling with related to providing premium SMS services.

We have structured this paper as follows. First, the concepts of value networks are introduced as an analytical lens to understand the context of providing premium SMS services. Next, based on our empirical research we describe the provision of ringtones for mobile phones, the network the usability of ringtones builds on and the actors it involves. Finally, we draw conclusions on how the insights provided in this paper can contribute to the provision of premium SMS services in the service provision context. 


\section{VALUE NETWORKS}

Some of the aspects related to developing premium SMS services and usability fit neatly into the prevailing system development methods and approaches. Typically, this is related to the relative disadvantage of phones with their small screens, limited bandwidth and processing capacity and cumbersome input interface, as well as the challenge of preparing the content in an appropriate format (discussed by for example Hjelm 2000; Tarasewich 2003). However, meeting the usability challenges with this approach is not necessarily sufficient. As consumption of premium SMS services usually is triggered by impulse, usability is also close related to how the impulse is turned into consumption. First, when the impulse is triggered the necessary information to order the service must be simple and easily available for the end-user. Second, the acquisition process must run smoothly and not require a cumbersome registration process as not to obstruct the impulse. Within this context, usability can only be enabled by agreements between e.g. mobile network providers, content providers and media windows providing services to each others. By this constellation, usability can be achieved in the sense that the need for relative complex instructions for and process of service consumption is avoided.

These challenges are brought by the service providing context and materialize in a distributed and fragmented network of service provision and a multiple of user - developer relations. As a design recommendation we suggest an analytical lens to support the analysis and understanding of this context as well as how usability to the end-user can be provided.

To identify and make explicit the actors, their relations and the services they provide related to premium SMS services, we suggest using the conceptual framework of value networks developed by Stabell and Fjellstad (1998). The framework provides analytical support for appreciating a network of actors and their indirect mediation of relations through service provisioning. The concept of mediation in particular appreciates the actors (mediators) that bring together actors that complement each others, as for example mobile network providers mediating between the content providers and the end-users.

Value networks are composed of actors mediating between other actors, typically as providers and users of services. The network is thus not the constellation of the actors, but the mediating services they provide. The primary activities of such a value networks are: network promotion and contract management, service provisioning and network infrastructure operations (Stabell and Fjellstad 1998). Network promotion and contract management are the activities of bringing new actors to the network and governing contracts related to service provisioning and charging. Service 
provisioning is the provision of the mediating links, as well as billing through the measurement of network usage. Network infrastructure operation is maintaining the infrastructure necessary to handle requests of the actors.

The concept of value networks in particular provides us with two important conceptual tools supporting our analysis and appreciation of provision of premium SMS services. First, it makes us focused on the networked nature of and multiplicity of mediators and their mediations in the network. Second, it makes explicit the challenges of the central activities necessary to build and maintain the network necessary to create usability and provide premium SMS services per se. With such a perspective we understand successful provision of SMS services, in particular related to usability, as a result of a dispersed network of services and service providers. Designing usability thus becomes the activities of creating and maintaining this network.

\section{NETWORKS, SERVICES AND USABILITY}

Ringtones is one typical example of the networked nature of premium SMS services. Ringtones are primarily made available for the end-user by mobile network providers providing acquisition services, composed of billing and transportation services. However, other services such as copyright handling (by NPRS ${ }^{10}$ in Norway), mobile service subscription and advertising through media windows such as TV-shows and magazines, are equally important for the usability of ringtones for the end-user. With a value network perspective, there is not only one group of users, and actors can both appear as users and service providers from different perspectives in the network of relations (figure 1).

We may be led to understand ringtones as based on as a simple indirect mediating structure between content providers and end-users by the mobile network providers. However, the provision of premium SMS services is not simply built on one exchange relationship or one value chain, but on several levels of mediating services in a network of value chains (Stabell and Fjellstad 1998). We thus draw a more complex, but also more encompassing picture of the network of mediating services and relations between actors in figure 1 . We at the same time stress that this picture should be interpreted as our initial conceptualization of a network that is very much in change with actors entering and leaving the network.

${ }^{10}$ Norway's Performing Rights Society 


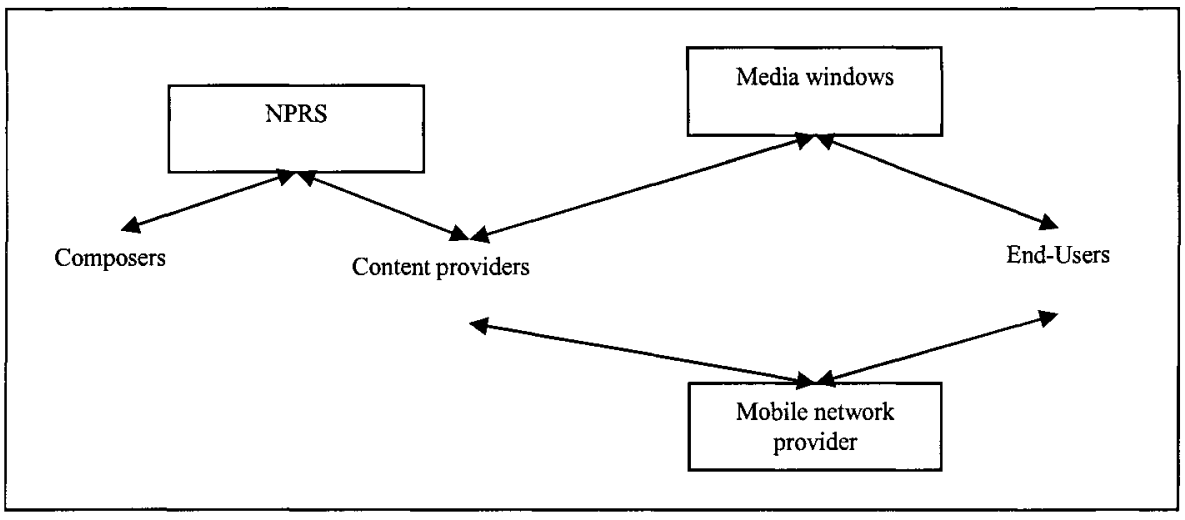

Figure 1. A value network of mediating relations

Providing the required usability of ringtones would not have been feasible without the acquisition services provided by the network providers, the advertising with instructions for how to order the ringtones provided by the media windows and the handling of intellectual property rights by NPRS. Even if service providers tend to see their role as the primary in the network, the complementary nature of the whole network makes all the actors and their mediating roles and provision of services a necessity in the network.

\subsection{From developing a system to providing one service in a network of services}

In this paper we ask for a change of focus from the system perspective to the service perspective in system development (e.g. Dahlbom 2003). In particular, a service perspective points at the nature of service provision as ongoing interactions between service providers and users. Within this context, exemplified by premium SMS services, the content services are complementary to network services that again are enabled by infrastructure services, as e.g. acquisition and access services. In the case of premium SMS services, the usability for the end-users is the result of reducing the complexity by media windows displaying the content and how to order it, the various mobile network providers coordinating common prizing and access numbers while also taking care of the billing.

When engaged in providing premium SMS services, a single system or interface focus makes little sense related to creating usability for the endusers. Usability and the end-user' experience is based on the combination of a range of systems and services. As system developers, we may find our selves in the middle of this network and without any direct relation to the end-user, even if we are making up the total usability. But only together, the 
various systems, services and relationships enable the provision of premium SMS services with the required usability. The basic prerequisite for the creation of such a network is for the various actors understand their role as well as appreciate the roles and the value of the other actors in the network.

\subsection{Multiplying the gaps and redefining the role of mediators}

Based on a common appreciation of the networked nature of premium SMS services, the relationships making up the network of mediators can be developed and maintained.

Raising the concerns about the lack of involving end-users in system development and the consequences for usability, Grudin (1991) introduced a framework describing how various system development contexts affect the user - developer relationship. The contexts discussed by Grudin are primarily based on when users and developers are identified during the development process, as in: Contract development, product development and in-house development. Describing in detail how conditions for user participation vary across these contexts, Grudin illustrate a range of mediators that bridge the gap between users and developers that occurs in the different contexts, both in time as well as space. These mediators, as for example domain experts or consultants, are however to be continually reexamined as they are only indirect and not as effective as direct user developer interaction when designing usability.

Providing premium SMS services exemplifies another context for user developer relationships. This context and the relationship between users and developers do at the same time challenge the framework developed by Grudin on three critical issues.

First, successful provision of premium SMS services is not solely based on one actor, but rather builds on a network of actors, services and mediators. Thus, providing services is not built on one, but multiple of user developer relationships. The challenges for system developers are thus not only to develop systems and services, but also to develop and maintain these relations. Within this process, the responsibility and ability to provide usability becomes fragmented among the different actors, and there is no focal point where the totality of usability is coming from. Usability is not primarily a design or construct, but a result of the assembly of a range of different services

Second, even if Grudin questions whether it is possible to pin down in time when users and developers are known to each others, the project timelines he discusses are of a linear nature. Providing services, however, builds on a range of mediating services, services developed with multiple 
and overlapping timelines. If these projects are not coordinated, different actors may end up in a "chicken and egg" debate (discussed by for example COM 2002; Funk 2001). Without a close relationship between the various service providers, they will mutually be engaged in a highly complex and unpredictable context. On the other hand, providing incentives such as attractive revenue share models will engage other actors and facilitate coordinated timelines.

Third, in the contexts described by Grudin mediators bridge the gaps between users and developers, even if not as efficient as with a direct user developer relationship. In providing services, mediators also play a very important part of the value network. For the final product; premium SMS services in our case, these different actors all contributes to usability. However, in our context mediators are the very substance of providing services - not only a stopgap and a substitute to bridge a gap a temporarily, but a permanent part of the design. Mediators are not conduits for usability information and inputs, but are equally important in providing usability themselves.

\subsection{The changing role of the system developer}

As the responsibility for providing the network of services is distributed, system developers related to providing of premium SMS services will be situated in one of the nodes in a network of services. Their role will first be to develop, maintain and provide the necessary "technical" service level to enable the network of mediations as well as enrolling the potential customers. Second, system developers have to make sense of, appreciate, engage and enroll the associated actors and layers of mediating networks that are necessary to make up the complete network. These other actors do at the same time not necessarily have their mediating network up and running, at the same time as they will follow their own agenda and nurture their own interests. Their different interests and agendas may or may not be in conflict, and may or may not promote and enable a successful network of services. Third, to overcome these challenges system developers must develop and promote a business model that is attractive for other actors to engage in and further invites to innovation.

According to this perspective there is much more than only one user developer relationship. And the challenges for system developers are not only to engage with the end-users of premium SMS services to increase the usability of the system, but basically to understand who their users are. Further, system developers must understand their own role as users in a network that only as a whole provides usability of premium SMS services. 


\section{CONCLUSION}

One fundamental challenge for providing premium SMS services is usability. However, usability related to these services is not primarily the design of their appearance on the mobile phone. Creating and maintaining relationships among the various and complementary service providers becomes the most central issue to develop usability even if including endusers in the process does not become less significant. Rather, the complex network of actors involved will question who should engage in and be responsible for the relationships with the end-users.

Providing premium SMS services is a complex endeavor. Taking the issues we have discussed in this paper seriously reveals new challenges for system development, as well as it brings new perspectives on what a service consists of. More than technology, services are built on a network of mediating services enabled by relations between a range of different actors. To capture the dynamics of these networks we have suggested analyzing and describing the context with the concepts of value networks. Then, it becomes evident that the challenge for system development is simultaneously to analyze, appreciate and take these networks seriously, and to enroll other actors necessary to make up a complete network. To enable this shift, we extend our perspective from the simple user - developer relation and the single project timeline, to also include those mediating relations that enable the provision of services and how they can be maintained over time.

In this paper we have describe a context that includes a range of user developer relationships. We have shown the importance of engaging users in the development of services, but users from one perspective are developers from the other. As system developers, we will thus find our selves in different places in the network and with different roles at different times. While end-user involvement still is a necessity to accomplish the network, system developers are also the users. How to appreciate the users, to what extent to involve them and on who' terms is, however, an open question.

A focus on creating, handling and maintaining these kinds of relations has not been a part of system development methods and agendas. Whether this new context and perspective should involve new system development models is an open question, and it has not been the scope of this paper to provide a full fledged approach or methodology to handle this challenge. Our contribution is rather describing one case where we have shown the necessity of a network perspective and to guide system developers to look at their roles from a different perspective when they develop and provide premium SMS services. 


\section{REFERENCES}

Anckar, Bill, and Davide D'Incau. 2002. "Value-Added services in Mobile Commerce: An Analytical Framework and Empirical Findings from a National Consumer Survey." in HICSS-35. Hawaii: IEEE.

Carlsson, Christer, and Pirkko Walden. 2002. "Further quests for value-added products \& services in mobile commerce." Pp. 715-724 in ECIS 2002. Gdànsk, Poland.

COM. 2002. "Digital Content for Global Mobile Services: final report." Brussels: European Commission: Directorate-General Information Society.

Dahlbom, Bo. 2003. "From users to consumers." Scandinavian Journal of Information Systems 15: 105-108.

Funk, Jeffrey Lee. 2001. The Mobile Internet: How Japan dialed up and the West disconnected. Kent, UK: ISI Publications.

Grudin, Jonathan. 1991. "Interactive Systems: Bridging the Gaps Between Developers and Users." IEEE Computer 24: 59-69.

Hjelm, Johan. 2000. Designing wireless information services: John Wiley \& Sons, Inc.

Nielsen, Petter, and Ole Hanseth. 2003. "Enabling an Operator-Independent Transaction Model for Mobile Phone Content Service Provision Through the Open CPA Platform." Pp. 344-353 in Proceedings of the Workshop on Standard Making: A Critical Research Frontier for Information Systems, edited by John L King and Kalle Lyytinen. Seattle, WA.

Stabell, Charles B., and Øystein D. Fjellstad. 1998. "Configuring value for competitive advantage: On chains, shops, and networks." Strategic Management Journal 19.

Sørensen, Carsten, Lars Mathiassen, and Masao Kakihara. 2002. "Mobile Services: Functional diversity and Overload." in New Perspectives On 21st-Century Communications, edited by K. Nyiri. Budapest, Hungary.

Tarasewich, Peter. 2003. "Wireless Devices for Mobile Commerce: User Interface Design and Usability." in Mobile Commerce: Technology, Theory and Applications, edited by Brian E. Mennecke and Troy J. Strader. Hersey US: Idea Group Inc.

van de Kar, Elisabeth, Carleen F. Maitland, Uta Wehn de Montavlo, and Harry Bouwman. 2003. "Design guidelines for Mobile Information and Entertainment Services: based on the Radio538 ringtunes i-mode service case study." in 5th international conference on Electronic commerce. Pittsburg, Pennsylvania: ACM. 